\title{
Moderating effects of governance quality on the relationship between stock liquidity and dividend in emerging market countries
}

\begin{abstract}
The paper examines the moderating effects of governance quality on stock liquidity and dividend relationship. Past empirical studies on the link between stock liquidity and dividend suggest there are mixed findings between them. A negative relationship suggests stock liquidity and dividend are a substitute which aligns with the liquidity hypothesis. On the other hand, a positive relationship between stock liquidity and dividend suggests stock liquidity informational effect increases a firm's incentive to pay dividends. Moderating factors could have contributed to such mixed findings. Therefore, this study suggested governance quality could be one of the moderating factors that contributed to the inconsistency findings. Governance quality has been known to mitigate information asymmetry that made firm pay more dividends by formulating and promoting sound policies. Thus, this study aimed to ascertain the moderating factors of governance quality on the relationship between stock liquidity and dividend. By using a sample from 22 emerging market countries, we adopted logistic panel random effect to estimate the model. Adopting the governance quality measurements developed by the World Bank, our empirical results found that political stability, government effectiveness, regulation quality and control of corruption are among the factors that moderated the relationship between stock liquidity and dividend.
\end{abstract}

Keyword: Stock liquidity; Dividend; Governance quality; Information asymmetry 